\title{
OLHAR, LUGAR, VAZIO: O TEATRO CRÍTICO DE RAÚL ANTELO
}

\author{
Paula Glenadel \\ UFF - CNPq
}

RESUMO: 0 artigo propõe um breve comentário sobre a obra crítica do professor e pesquisador Raúl Antelo, que é aqui apresentada em termos de um singular teatro crítico, para 0 qual as categorias de olhar, de lugar e de vazio têm importância fundamental. Através de algumas referências a essa obra, contidas em textos publicados entre os anos 2000 e 2014, bem como também a suas principais fontes de inspiração teórica, estudar-se-á a maneira como, nela, a complexa articulação entre experiência e experimentação promove uma renovação dos lugares do sujeito e do objeto, polos tradicionais do exerććcio do conhecimento.

PALAVRAS-CHAVE: Crítica; Teatralidade; Conhecimento.

\section{LOOK, PLACE, EMPTINESS: RAÚL ANTELO'S CRITICAL THEATER}

ABSTRACT: This article proposes a brief commentary on the critical work of professor and researcher Raúl Antelo, which is here presented in terms of a singular critical theater, for which the categories of look, place and emptiness are of fundamental importance. Through some references to this work, contained in texts published between 2000 and 2014, as well as to its main sources of theoretical inspiration, we will study the way in which the complex articulation between experience and experimentation promotes a renewal of the subject and object places, traditional poles of the exercise of knowledge.

KEYWORDS: Criticism; Theatrality; Knowledge.

Paula Glenadel é Professora Titular da Universidade Federal Fluminense e pesquisadora e vice- coordenadora do Programa de Pós-graduaçãa em Estudos de Literatura desta mesma instituição. 


\section{OLHAR, LUGAR, VAZIO: O TEATRO CRÍTICO DE RAÚL ANTELO ${ }^{1}$}

\section{Paula Glenadel}

Em uma entrevista concedida à revista Interartive em 2014, ao sabor das perguntas que lhe são feitas sobre o seu procedimento crítico "godardiano", Raúl Antelo evidencia algo que já vem se insinuando há tempos em seu pensamento-escrita, de forma cada vez mais explícita: a existência de toda uma prática da montagem que lhe dá sustentação, e que permite descrevê-lo como um teatro crítico, onde as categorias de olhar, de lugar e de vazio têm importância fundamental. Para efeito dessa descrição, retomarei algumas das propostas de Antelo, que serão aqui organizadas de modo a criar um espaço de reverberação dos desvios, das derivas e dos recomeços desse pensamento-escrita.

A montagem praticada por ele aparece primeiramente como o olhar crítico que aproxima, em contraste, o objeto canônico daquele objeto que poderíamos qualificar de "aleatório", ou seja, aquele que não foi escolhido em função das suas qualidades intrínsecas, à diferença do canônico, que pode ser considerado como superior, porém apenas desde a perspectiva de "uma compreensão apriorística, idealista, kantiana, mais tradicional". ${ }^{3}$ O objeto aleatório funciona como um ready-made anestético, aquele precisamente com o qual se mantém a relação de maior indiferença. Assim, Antelo diz:

Eu posso tranquilamente me interessar por objetos aparentemente desprovidos de valor, cujo valor é meramente contingente, porque é o meu olhar que vai promover a mudança ao estabelecer uma conexão com outros objetos, não raro alguns deles, sim, canônicos. Então, a questão não passa por juntar três ou quatro objetos sem valor, mas sim juntar o objeto valioso, canônico, consensual, com outro sobre o qual ninguém reparou ou nem acharam que pudessem pertencer à

\footnotetext{
${ }^{1}$ Este artigo corresponde a uma versão revisada do trabalho apresentado em 2014 no Museu de Arte do Rio - MAR, no evento Ficção crítica, Arquivos, Arqueologias - em torno do trabalho crítico de Raúl Antelo, organizado por Manoel Ricardo de Lima Neto e Maria Lucia de Barros Camargo.

2 Ideia que já surgia em 2010, recolhida por Rosângela Cherem, conforme relembra uma das entrevistadoras, Sandra Checluski: "[...] rememoramos a sua citação concedida à professora Rosângela Cherem para a revista Palíndromo, publicada em 2010, a qual aponta que seu método de escrita é absolutamente godardiano, ou seja, pura montagem".

3 FERREIRA, Josimar; BAHIA, Lucia; CHECLUSKI, Sandra. Sobre escrita, delírios e sensibilidades: Entrevista com Raúl Antelo. maio 2014.
} 
determinada área. Parece-me residir aí a capacidade de contagiar outras leituras. Não se contentar com o consenso tem uma dimensão ética, porque acaba de algum modo nos angustiando. $O$ crítico que não se angustia não me interessa. ${ }^{4}$

Obtém-se, através desse processo, um corte no tecido da tradição, uma percepção de choque, em que a ambivalência dos valores e a ideologia neles impregnada se encontram expostas, o que evoca, entre outros trabalhos que vão nessa direção, o estranhamento brechtiano. Este é comentado por Roland Barthes através da imagem do alfinete japonês munido de um guizo para não ser esquecido uma vez terminada a costura; Bertolt Brecht, entretanto, afirma Barthes, faz questão de manter o alfinete, em consonância com uma prática do abalo que é característica do seu trabalho. Esse abalo é uma "re-produção: não uma imitação, mas uma produção descolada, deslocada: que faz barulho" ${ }^{5}$, impedindo desse modo a ilusão de naturalidade do discurso.

A montagem seria, assim, da ordem do abalo. Mas, como adverte Antelo, ela também corre o risco de se tornar clichê, palavra de ordem disfarçada de senha. ${ }^{6}$ Frente a esse risco de perda da eficácia crítica, da agudeza do corte, seria preciso pensar a montagem a uma só vez sutilmente e radicalmente:

Como toda categoria, o conceito de montagem tem que ser usado cum grano salis. Essa história de que tudo agora é montagem, tudo é anacronismo, dá vontade de apagar tudo o que a gente escreveu e da capo, começar tudo de novo. Porque não é por usar uma categoria, fetichizá-la e torná-la chave que abre todas as portas, que os passos serão dados com maior segurança. Eu acho que devemos ter um gesto dúplice: acompanhar o que está se fazendo, mas, ao mesmo tempo, ter a suficiente sutileza para entender quando um conceito se torna um clichê. Quando um conceito se torna um clichê está dominado, pois o clichê é uma forma de estereotipia verbal. E quando a linguagem se torna estereotipada é porque ela foi invadida por uma certa necrose e começou a morrer. Ao perceber que alguma coisa começa a morrer, um galho começa a morrer, eu prefiro arrancá-lo para devolver viço à planta e que continue crescendo com mais força. Isto também é corte. ${ }^{7}$

Dando toda a sua importância a essa noção de risco, de que Antelo vem falando também com certa frequência (como, por exemplo, no painel da área

\footnotetext{
${ }^{4}$ Ibidem.

${ }^{5}$ BARTHES, Roland. Brecht et le discours : contribution à l'étude de la discursivité. In : Le bruissement de la langue. Essais critiques IV. Paris : Seuil, 1984, p. 244-245. (Tradução minha).

${ }^{6}$ Para relembrar a distinção deleuziana entre mot d'ordre e mot de passe. DELEUZE, Gilles; GUATTARI, Félix. Capitalisme et schizophrénie, tome 2 : Mille plateaux. Paris : Minuit, 1980, p. 139.

${ }^{7}$ FERREIRA, Josimar; BAHIA, Lucia; CHECLUSKI, Sandra. Sobre escrita, delírios e sensibilidades: Entrevista com Raúl Antelo, op. cit.
} 
de Letras apresentado no encontro da Anpoll ocorrido em $2011^{8}$ ), é possível construir um diálogo entre o "gesto dúplice", a combinação de ousadia e precaução reivindicada por ele tanto na crítica quanto na pesquisa, e a reflexão proposta por Michel Deguy acerca do olhar poético. ${ }^{9}$ Para ambos, trata-se de uma "ótica" que também se apresenta como uma "ética", uma vez que, aplicando-lhe as palavras de Antelo citadas anteriormente, ela "não se contenta com o consenso" e "se angustia" buscando reinventar o ponto de vista. Deguy interroga assim a relação entre o olhar e as coisas na experiência poética, retomando termos caros à experiência da modernidade, como a vidência rimbaldiana:

Uma fenomenologia da invenção do ponto da vista, ou vidência, ou "visão", é sempre importante que ela seja novamente tentada. A qual "boa distância" se mantém o "olhar" que opera na experiência "poética" em relação às coisas que ela busca mostrar dizendo-as? Qual é a "ótica" do escutar-ver em poema? Um de longe que é um alhures-próximo caracterizaria esse ponto de vista [...]. ${ }^{10}$

A questão fundamental do poema é, portanto, a de dosar, de alternar o próximo e o distante, e vem a ser figurada através do olhar poético que, nessa operação, se torna simultaneamente olhar crítico, produtor e não imitador, desnaturalizante e não contemplador do que estaria já-aí. Pois o que está aí para ser visto é tanto o visível quanto o invisível:

Como no teatro, a relação do Espetáculo, onde se expõem e se abrigam "atores", não se faz com o público, mas com um terceiro, fonte invisível ou trama da visualidade. [...] e assim os espectadores sentem que não se trata somente, nem mesmo principalmente, de uma relação com dois termos em face a face, adversa, mas que há lugar para aquilo que dá lugar e que isso olha, aquilo que espaça uns e outros de uns e outros: e às vezes, atores ou público, eles erguem os olhos - como Fedra

\footnotetext{
8 "Post-scriptum. No debate que se seguiu a essa apresentação enfatizei que, a meu ver, faltava ousadia, faltava risco, em boa parte das pesquisas atuais em Literatura. Alguns colegas me pediram para aprofundar o conceito. A posteriori descobri, na imprensa, as declarações de Antonio Candido, quase 93 anos, na reportagem concedida por ocasião da Festa Literária Internacional de Paraty (Flip), justamente na véspera da reunião da Anpoll: falta risco na crítica acadêmica. Magister dixit." É o que diz Antelo ao final dessa apresentação, mesclando (inclusive mixando) sua reflexão com a casual atualidade da reflexão de outrem. ANTELO, Raúl. Diagnóstico da comunidade de Letras - Anpoll 2011. Revista da Anpoll, n. 33, p. 283, jul. /dez. 2012. [Literatura: linguagem, história e acontecimento].

${ }^{9}$ Em textos posteriores de Deguy, essa reflexão vai se desdobrando e culmina na noção de diplopia, utilizada para evocar o jogo do pensamento poético entre a ilusão e a figura, entre o ver e o crer ver. Cf. por exemplo, DEGUY, Michel. Le sens de la visite. Paris: Stock, 2006, p. 90-91.

${ }^{10}$ Idem, De la contemporanéité. Causerie pour Jacques Derrida. In: MALLET, Marie-Louise (Org.). Le passage des frontières. Autour du travail de Jacques Derrida. Paris: Galilée, 1994, p. 222. (Colloque de Cerisy 1992; Tradução minha).
} 
na direção desse sol de quem eles descendem, ou como Mallarmé na direção do lustre da ópera... ${ }^{11}$

A noção de teatro já contém, como é sabido, uma referência ao ver ${ }^{12}$, que subjaz à comparação reflexiva de Deguy. Assim, o teatro tem a ver com o ver e, por isso, é preciso se aproximar, mas também se afastar dos objetos, e do seu próprio olhar, em busca desse lugar vazio que a montagem expõe e que dá sentido a todo e qualquer sentido. Esse olhar contém uma exigência que é ética também porque ela implica a necessidade de perceber sempre um totalmente outro, esse "terceiro" irredutível, que é outro tanto em relação ao público quanto em relação aos atores, extrapolando e fundando a relação deles.

Partindo dessas considerações é que encontro nos movimentos da crítica anteliana uma teatralidade que me interessa destacar. Dez anos antes da entrevista citada no início deste texto, em 2004, Antelo evoca em outro depoimento a sua prática de leitura-em-montagem, dessa vez em modo borgeano: "Fiz do anacronismo deliberado e da atribuição errônea uma ética de leitura." ${ }^{13}$ Cabe dizer que tal ética aparece no contexto desse depoimento como correlata a uma "reconfiguração da subjetividade" ${ }^{14}$ e ao "exame das relações entre lei e verdade". ${ }^{15}$

Assim, por exemplo, em um texto de 2006, lendo o poeta Juan L. Ortiz através de uma proposta crítica de Tamara Kamenszain, Antelo ressalta que essa autora "alude à construção do semblante em Juanele. Numa autopoiesis abismal, nos diz Tamara, o poeta cria a si próprio como criou também sua paisagem." ${ }^{16}$ Essa abordagem vai encontrar correspondências com uma proposta mais recente de Antelo (de 2012), segundo a qual

\section{[...] aquilo que está para ser feito, o que se pesquisa como ato de per quaere, não se situa nunca no registro de uma poiesis, como uma obra cujo esquema já estaria previamente traçado, mas no registro de uma praxis que, de relevante, só produz mesmo, retrospectivamente, seu próprio agente. ${ }^{17}$}

\footnotetext{
11 Ibidem, p. 222.

12 Breve lembrete da etimologia da palavra : "Ce terme vient du grec theatron, et le theatron signifie le lieu où l'on assiste à un spectacle, à savoir : la salle. Le theatron est composé de thea qui signifie action de contempler (faite par le public) et spectacle (produit par les acteurs). On remarque donc, dès l'origine, un sens équivoque du mot, qui hésite entre scène et salle, entre acteurs et public." RUNTZ-CHRISTIAN, Edmée. Enseignant et comédien, un même métier? Issy-les-Moulineaux, ESF Éditeur, 2000, p. 32.

${ }^{13}$ ANTELO, Raúl. Entre miradas. Outra Travessia, n. 3, p. 15, 2004.

${ }^{14}$ Idem, p. 16.

15 Ibidem.

${ }^{16}$ ANTELO, Raúl. Visão e pensamento. Poesia da Voz. In: Crítica e ficção, ainda. Florianópolis: NELIC/UFSC/Pallotti, 2006, p. 35.

17 Idem, Diagnóstico da comunidade de Letras - Anpoll 2011, op. cit., p. 276.
} 
Pelo viés do foco na reconfiguração da subjetividade, há um atravessamento do lido e do leitor. Pode-se compreender que aquela autopoiesis anteriormente apontada corresponde a um desvio, uma deriva da poiesis comentada aqui acima, isto é, ela se reconfigura e aparece de fato como uma praxis, no sentido em que ela não dispõe de itinerário prévio. A perspectiva da teatralidade oferece à crítica anteliana, assim, uma possibilidade de ler essa "reconfiguração da subjetividade" de múltiplas maneiras singulares, uma para cada autor lido, deslocando-se e reconfigurando-se também nesse exercício, o que a mostra como bastante próxima da visão batailliana do conhecimento, onde

\begin{abstract}
Não há mais sujeito=objeto, mas "brecha aberta" entre um e outro e, na brecha, o sujeito, o objeto são dissolvidos, há passagem, comunicação, mas não de um a outro: um e outro perderam a existência distinta. As questões do sujeito, sua vontade de saber são suprimidas: o sujeito não está mais ali, sua interrogação não tem mais nem sentido nem princípio que o introduza. Do mesmo modo, nenhuma resposta permanece possível. A resposta deveria ser "tal é o objeto", quando já não existe mais objeto distinto. ${ }^{18}$
\end{abstract}

A teatralidade, além disso, liga-se ao "exame das relações entre lei e verdade", pois a leitura de Antelo, ao mesmo tempo em que se interessa pela teatralidade do gesto autopoiético de Juanele, registra que a categoria de infância nesse poeta "funciona, assim, como o branco de Mallarmé. É o espaço da disposição do êxtase" 19 , prevenindo a clausura e aproximando-se de um exercício de soberania, no qual uma torção do poema "impede toda e qualquer leitura literária". ${ }^{20}$ "Literário" aqui significaria o não ético, o meramente estético num sentido tradicional, programático; é a razão pela qual é preciso ultrapassá-lo na direção da reconfiguração teatral de um sujeito em devir. Como a poesia, a crítica contemporânea aposta nessa virada, nessa saída, em direção ao êxtase ou ao impossível, para falar ainda com Georges Bataille. ${ }^{21}$

Essa teatralidade ética da crítica fornece, portanto, um ponto de vista para refletir sobre o funcionamento do trabalho de Antelo, entendido como um teatro crítico que põe em cena o lugar do sentido como vazio. Ele procederia, ademais, por um movimento dúplice e oscilatório na leitura dos seus

${ }^{18}$ BATAILLE, Georges. L'expérience intérieure. Paris : Gallimard, 1954, p. 74. (Tradução minha).

${ }^{19}$ ANTELO, Raúl, Visão e pensamento. Poesia da Voz, op. cit., p. 37.

20 Ibidem.

${ }^{21}$ No sentido em que "[...] la poésie mène du connu à l'inconnu". BATAILLE, Georges. L'expérience intérieure, op. cit., p. 157. (Tradução minha). 
objetos. De um lado, a categoria de experiência ${ }^{22}$, assombrada pela distância, diferença e dessubjetivação, tal como ela aparece no testemunho de Pinnie Wald, Koshemar, por exemplo, sobre o qual Antelo observa que, para escrevê-lo, seu autor abstrai o olhar fixando uma mancha na parede da delegacia, "de tal modo que cinde seu objeto e transforma o ocularcentrismo cotidiano em uma peculiar estereoscopia de sua condição desamparada." 23 De outro, a categoria de experimentação, ligada ao aspecto "obtuso" das ficções que sublinha a inscrição de todo valor "na ordem do acaso". ${ }^{24}$

A complexidade das referências antelianas é grande, e a árdua reflexão suscitada por elas exige, por vezes, percorrer vias extremas. Vem daí, por exemplo, essa separação inicial entre os dois campos da experiência e da experimentação, que é aqui essencialmente metodológica, ou seja, essencialmente não essencializante, como cabe indicar. Para acompanhar as peripécias, os acontecimentos imprevistos, os coups de théâtre desse pensamento, finge-se por um momento compartilhar de uma visão tradicional que toma os dois aspectos no campo de uma oposição fixa, finge-se por um momento esquecer formulações como as de Jacques Derrida, que propõe que "Há um gênio do testemunho que nos lembra que o ato testemunhal é poético ou não existe, a partir do momento em que ele deve inventar sua língua e formar-se num performativo incomensurável" 25 , ou ainda as formulações de Roland Barthes que, com a categoria do biografema, abala as fronteiras entre o que toca ao corpo e o que toca à escrita. ${ }^{26}$

Essa separação metodológica considera o ponto de partida de cada categoria: a experiência partiria da história, e consagraria a vida como invenção verdadeira de um narrador, ainda que sua função narrativa o distancie da vivência do sujeito; a experimentação partiria da ficção, do obtuso, do sem-fundo do sentido que excede toda explicação, e consagraria a invenção de um artista como a verdadeira vida, no sentido da forgery joyceana, já comentada por Antelo em relação às galáxias de Haroldo de Campos. ${ }^{27}$ Ambas as cate-

${ }^{22}$ Essas categorias, experiência e experimentação, foram propostas pelo grupo de trabalho do convênio UFF - UNTREF para fundamentar um encontro de pesquisadores em Niterói em 2014, intitulado Literatura e translínguas: poéticas e políticas da experiência, onde apresentei um esboço deste artigo.

${ }^{23}$ ANTELO, Raúl. El vidrio y los insectos. Hispamérica, v. 88, p. 22. (Tradução minha).

24 Idem, Genealogia do vazio. Rivista di Studi Portoguesi e Brasiliani, v. 1, p. 57, 1999.

${ }^{25}$ DERRIDA, Jacques. Demeure. Maurice Blanchot. Paris: Galilée, 1998, p. 109. (Tradução minha).

${ }^{26}$ BARTHES, Roland. Sade, Fourier, Loyola. Paris: Seuil, 1971, p. 14. (Tradução minha).

${ }^{27}$ ANTELO, Babel e a harmonia grotesca. In: PEDROSA, Celia; ALVES, Ida (Org.). Subjetividades em devir. Rio de Janeiro: 7 Letras, 2008. 
gorias, porém, serão retomadas logo adiante, em sua conjugação que cria arranjos improváveis, reinventando a cada vez, a cada aparição, sua relação, sua mistura, para compor uma leitura, um modo de leitura, através de uma escuta extremamente fina de uma multiplicidade de textos lidos em rede.

Talvez a razão de ser dessa separação esteja também ligada à tentativa de distinguir aqui, de maneira igualmente precária, dentre as matrizes filosóficas desse pensamento, uma linhagem benjaminiana e uma linhagem nietzschiana, duas abordagens não excludentes, porém investidas de um pathos distinto, cada uma encarregada de performar certas funções nesse espaço crítico, onde as reencontraremos em movimento. Além de Walter Benjamin e Friedrich Nietzsche, também estão presentes diversos pensadores vinculados a cada uma dessas matrizes, como Giorgio Agamben, Georges Didi-Huberman, Georges Bataille, Jacques Derrida, Jean-Luc Nancy, Roland Barthes, Michel Foucault, dentre os mais frequentemente convocados. De maneira muito especulativa, creio que seria possível identificar essas funções como, no caso de Benjamin, através da noção de imagem dialética, a de expressar o sentido como experiência, o que falaria da teatralidade como aparição anti-historiográfica; e no caso de Nietzsche, através da noção de eterno retorno, a de expressar o sentido como experimentação, o que enfocaria a teatralidade como dramatização genealógica de valores recalcados.

Tudo aqui exige ser tomado, como logo se percebe, "cum grano salis". A precaução de evitar generalizações, recomendada nessa fórmula recorrente nos textos antelianos, não deixa de funcionar à maneira de uma discreta assinatura. Ela inspira em seu leitor um movimento como aquele evocado por Derrida, que consiste na contra-assinatura que reconhece a marca, re-marcando-a - o termo utilizado é re-marque, onde se lê a marca (marque) e a sua percepção (remarque), mas também sua repetição (re-) ${ }^{28} \mathrm{O}$ movimento dessa leitura que re-marca, contudo, carrega uma ambivalência. Ele se arrisca a fixar a assinatura em uma repetição maquinal, isolada do movimento muito mais interessante de um acontecimento textual; arriscando-se, portanto, à contra-assinatura, entendida desta vez como destruição insensata da capacidade que aquele texto tem de lhe dar prazer (a assinatura sendo recebida pelo leitor como um dom jubilatório, dom da obra). Eis, então, que novamente surge o risco, que é também chance de risco, o grão de loucura (para fiar a

${ }^{28}$ O termo se espalha por muitos textos de Derrida; poder-se-ia citar aqui, apenas como referência, escolhendo os livros dedicados à leitura de poetas, Signéponge e Schibboleth - Pour Paul Celan. 
metáfora anteliana do grão de sal) misturado à trama da lógica mais cautelosa (mas, sem esse grão, cair-se-ia na autoimunidade da razão). ${ }^{29}$

Ainda sobre o grão, pode-se lembrar Barthes, que não era insensível a certo erotismo da leitura (isto é, o desejo do leitor pelo autor, sendo em última análise também desejo de se tornar autor), para quem o grão da voz corresponderia à ressonância do corpo do autor na escrita, lugar de passagens entre o mundo e a linguagem. O que proporcionaria uma possibilidade de articulação (vale a pena sublinhar que ela se dá como oscilação, não como fusão homogeneizadora) entre experiência e experimentação.

Evocando também, ainda que de maneira muito superficial, uma fórmula amplamente difundida, que diz ser preciso "Separar a palha das palavras ( $a$ forma, a expressão) e o grão das coisas (o fundo, a substância)", chegar-se-ia a um ponto fundamental, a questão sem fundo da linguagem. Então, justamente, entre experimentação e experiência, está em questão o jogo entre "as palavras e as coisas", que aqui, entretanto, não apenas se esquivaria ao imperativo de uma separação, como também trabalharia no sentido de enredá-las. Pode-se declinar ou distorcer indefinidamente esse paradigma, mas tudo parece girar em torno dele. Assim, tem-se linguagem e corpo; estética e ética; bíos e zoé; infinito e finito; e quiçá inclusive o par moderno e anti-moderno (ou pós-moderno).

Toda uma vertigem assombra essas séries de termos que não se distinguem nem se identificam totalmente. Deles, se alimenta o olhar crítico de Antelo, que faz do mimetismo (sem mimese) o "ponto ambíguo de uma inter-dicção e de uma pulsão. É, ao mesmo tempo, colonial e pós-colonial, semelhança e semblante, collège e collage." ${ }^{30}$ No lugar do enodamento que esses termos convocam ao se apresentarem em um jogo de oposição, pode-se entrever o impossível. Aqui, como aponta Antelo, o poema pensa a linguagem em seu intercâmbio com o sujeito,

\section{[...] em um espaço vazio, onde rien n'aura eu lieu que le lieu, ou em outras pala- vras, o situa na cena teatral do vazio de sentido, onde o texto é o lugar que se põe a si mesmo em jogo, se questiona, muda, se move e acaba por tornar-se sujeito. Um logodédalo. Por um efeito especular, então, o sujeito se torna enunciado e ali reencontra a reciprocidade de uma cena, aquilo que Jean-Luc Nancy e Lacoue-}

\footnotetext{
${ }^{29}$ Cf. por exemplo, DERRIDA, Jacques. Voyous: deux essais sur la raison. Paris : Gallimard, 2003.

${ }^{30}$ ANTELO, Raúl. Genealogia del mimetismo: estúdios culturales y negatividad. In: Mabel Moraña. (Org.). Nuevas perspectivas desde/sobre América Latina. El desafío de los estudios culturales. Santiago/ Pittsburgh: Cuarto Propio / Instituto Internacional de Literatura Iberoamericana, 2000, p. 385. (Tradução minha).
} 
Labarthe discutem, precisamente, em Scène, quer dizer que Mallarmé vê o signo como um espectro de sentido. ${ }^{31}$

Esse jogo de inversão também poderia ser entendido como uma meditação radical reverberando a noção mallarmeana do pensamento como "teatro mental". Assim, pode-se enxergar nas operações críticas antelianas um processo de encenação vertiginosa, cujos personagens são textos canônicos, textos "menores", autores, teorias e figuras, títulos e assinaturas, e onde o cenário é o vazio, ou o branco. Deixados sobre um palco vazio de sentido, personagens encarnando valores diversos disputam a cena em um jogo de forças, como o hino nacional argentino, os hinos de Hölderlin e o poema de Lamborghini, "Seol"; 32 como a visão ao mesmo tempo contra o comércio escravocrata e antiabolicionista da mestiça condessa de Merlin e os poemas de Baudelaire; ${ }^{33}$ como Maria com Marcel ${ }^{34}$, enfim, espécie de correspondente anteliano da dupla espectral Kant com Sade pensada por Lacan.

Da capo. A cada vez, há o recomeço do pensamento, com novas aparições, novos personagens, novas vozes. Apesar da aparência imponente, monumental dos textos antelianos, não se trata aqui de desejo pelo saber absoluto. É preciso cortar o que se havia montado, desconstruir o que se havia erigido, jogar fora o que se havia guardado. É preciso jogar, bataillianamente, a despesa contra a acumulação, a comédia contra a totalidade.

Essa teatralidade questiona fundamentalmente, então, a teatralidade hegeliana do Geist, a entrada em cena triunfal do Espírito no momento decisivo, destinal, da História, em que ele se encontra consigo próprio; uma teatralidade reativa que exclui, por exemplo, a África negra do palco da história universal, como apontado por Derrida na conferência sobre o perdão, a verdade e a reconciliação, onde ele analisa os acontecimentos após o fim do apartheid na África do Sul. ${ }^{35}$

A teatralidade em questão se aproxima da dualidade do sujeito encenada pelo poema, conforme a perspectiva de Agamben citada por Antelo. Ela fala do poema como "un calco o una maschera dell'io - o meglio, una dramatiz-

${ }^{31}$ Idem, Foucault, Mallarmé y la vida nordestina. Coloquio Internacional "Foucault y América Latina". UNTREF, 2014, mimeo, p. 9. (Tradução minha).

${ }^{32} \mathrm{Cf}$. Idem, Babel e a harmonia grotesca, op. cit.

${ }^{33}$ Cf. Idem, As flores do mal: sintoma e saber anti-modernos. Alea, v. 9, n. 1, jan./jun. 2007.

${ }^{34}$ Cf. Idem, Maria com Marcel: Duchamp nos trópicos. Belo Horizonte: Ed. UFMG, 2010.

35 DERRIDA, Jacques. O perdão, a verdade, a reconciliação: qual gênero? Tradução de Evando Nascimento. In: NASCIMENTO, Evando. (Org.). Pensar a desconstrução. São Paulo: Editora Estação Liberdade, 2005. 
zazione o una teatralizzazione a due voce del soggetto, del suo ritmo interno e dela sua intima scissione." ${ }^{36}$ Alinhado nessa direção, o teatro crítico de Raúl Antelo mantém aberto para nós esse lugar vital em que é "possível conservar a tensão entre tempo do segredo e tempo da história, ou melhor, é possível reconhecer modalidades de não-conhecimento no próprio sujeito." ${ }^{37}$

${ }^{36}$ ANTELO, Raúl, Babel e a harmonia grotesca, op. cit., p. 268, em italiano no original. 37 Ibidem. 